\title{
Serum and follicular fluid leptin levels are correlated with human embryo quality
}

\author{
Anifandis Georgios ${ }^{1,2}$, Koutselini Eleni ${ }^{1}$, Stefanidis Ioannis ${ }^{3}$, Liakopoulos Vassilios ${ }^{3}$, \\ Leivaditis Constantinos ${ }^{3}$, Mantzavinos Themis ${ }^{1}$ and Vamvakopoulos Nikolaos ${ }^{2}$ \\ ${ }^{1}$ 2nd Department of Obstetrics and Gynecology, University of Athens Medical School, Aretaieio Hospital, $76 \mathrm{~V}$. \\ Sofias Ave, 11528 Athens, Greece, ${ }^{2}$ Department of Biology and Genetics, and ${ }^{3}$ Department of Nephrology, \\ University of Thessalia Medical School, 22 Papakyriazi Street, Larisa 412 22, Greece \\ Correspondence should be addressed to G Anifandis, Department of Biology and Genetics, University of Thessalia Medical \\ School, 22 Papakyriazi Street, Larisa 412 22, Greece; Email: ganif@med.uth.gr
}

\begin{abstract}
This prospective study was undertaken to reassess the prognostic value of leptin during critical stages of in vitro fertilizationembryo transfer (IVF-ET) and address its role in the functional staging of assisted reproductive technologies at the level of embryo quality. Serum and follicular fluid samples of 100 selected women undergoing the long IVF-ET protocol were collected for leptin and embryo quality determination. The highest serum leptin concentration $(52.11 \pm 4.27 \mathrm{ng} / \mathrm{ml}) \mathbf{w a s}$ observed on ovum pick up day, while follicular fluid leptin was higher than all serum samples examined $(62.59 \pm 5.73 \mathrm{ng} / \mathrm{ml})$. Serum leptin above $59.48 \pm 7.6 \mathrm{ng} / \mathrm{ml}$ was associated with 'poor' embryo quality and above $56.87 \pm 5.52 \mathrm{ng} / \mathrm{ml}$ with pregnancy failure. Elevated leptin concentrations were associated with reduced ovarian stimulation and response, follicle maturation, embryo quality and pregnancy success. Our findings suggest that leptin modulates embryo quality and may serve as a sensitive marker of IVF outcome.

Reproduction (2005) 130 917-921
\end{abstract}

\section{Introduction}

Both natural and assisted human reproduction are complex multistage processes starting from gamete production and fertilization to embryo cleavage, transfer, implantation and development. The good quality of all reproductive components and primarily of embryos has a positive influence on live births. It is generally accepted that good embryo quality is a prognostic marker of pregnancy success and positive in vitro fertilization (IVF) outcome. The specific factors affecting embryo quality are poorly understood, although body mass index (BMI) appears to play a pivotal role in follicle maturation. The increased $\mathrm{BMI}$ of women of reproductive age has a negative influence in both natural and assisted reproduction. The pleiotropic hormone, leptin, the product of white adipose tissue (Zhang et al. 1994) is undoubtedly a major specific regulator of BMI that also modulates, through its membrane receptors located in the ovaries, follicles and testes (Cioffi et al. 1997, El-Hefnawy et al. 2000), critical aspects of human development such as initiation and maintenance of puberty (Cheung et al. 1997) and reproduction (Barash et al. 1996). The intimate relationship between BMI and leptin favors the candidacy of the hormone as a potential regulator of embryo quality.
During the menstrual cycle leptin levels increase in the follicular phase and decline in the luteal phase (Hardie et al. 1997), suggesting a disproportional influence of estradiol elevation on leptin secretion (Mannuci et al. 1998, Riad-Gabriel et al. 1998). During IVF cycles, serum leptin rises in response to exogenous follicle-stimulating hormone (FSH) administration (Butzow et al. 1999). Some reports indicated that elevated serum and follicular fluid leptin levels may be used as predictive markers of assisted reproductive technology (ART) failure (Mantzoros et al. 2000), while others have associated the presence of higher serum leptin concentrations 12 days after embryo transfer to pregnancy success (Unkila-Kallio et al. 2001). The ratio of serum leptin to BMI was a better marker of pregnancy success than leptin alone (Brannian et al. 2001). Leptin, vascular endothelial growth factor (VEGF) and nitric oxide (NO) concentrations have been used to predict oocyte immaturity and 'poor' embryo development (Barroso et al. 1999).

We have recently presented correlational evidence demonstrating the conditional role of leptin and estradiol as prognostic IVF markers potentially regulating embryo quality (Anifandis et al. 2005). In view of the important, although in many aspects still controversial role of leptin in ART, we undertook to reassess the prognostic value of 
its fluctuations during critical stages of the IVF process and to address its potential role as a direct functional staging (Nomikos \& Vamvakopoulos 2001) marker of ART at the level of embryo quality.

\section{Subjects and methods}

Estradiol $\left(E_{2}\right)$ and leptin concentrations were determined in four serum samples (I-III and V) and in one follicular fluid (ff) sample (sample IV) collected at different stages of the in vitro fertilization-embryo transfer (IVF-ET) protocol, as detailed below. The ethics committee of Athens University Medical School approved this protocol.

One hundred selected women signed an informed consent, undergoing their first IVF cycle were enrolled in this study during 2004. Women with ovarian hyperstimulation syndrome and polycystic ovaries (PCO) were excluded from the study. The ovarian hyperstimulation syndrome was defined by serum estradiol levels greater than $5000 \mathrm{pg} / \mathrm{ml}$ on the day of human chorionic gonadotropin (hCG) administration ( 3 and 2 women from the ART success and failure group respectively), and PCO syndrome ( 2 and 4 women from the ART success and failure group respectively) was defined by the disproportional serum leptin increase in response to recombinant FSH ( $\mathrm{rFSH})$ administration compared with normal women. All women studied had basal $\mathrm{FSH}$ levels $<8.5 \mathrm{IU} / \mathrm{l}$. They received daily subcutaneous (s.c.) injections of $1 \mathrm{mg}$ luteal gonadotropin-releasing hormone $(\mathrm{GnRH})$-a leuprolide acetate (LA) according to the long IVF-ET protocol, initiated in the midluteal phase of the previous cycle. LA administration was continued until serum estradiol levels dropped to less than $50 \mathrm{pg} / \mathrm{ml}$ with concomitant loss of follicular activity by transvaginal ultrasound (US) examination. At that time, rFSH (Puregon, Organon and Gonal F, Serono) was administered at an initial dose of 3 to 6 ampoules per day and LA was decreased to $0.5 \mathrm{mg} /$ day s.c. Serum was obtained on day six of the cycle for the measurement of leptin and estradiol (sample I). The FSH dosage was modified according to the ovarian response of every woman, but the number of ampoules (75 IU per ampoule) never exceeded 6 per day. rFSH administration was continued until a minimum of 2 follicles reached a diameter of $18 \mathrm{~mm}$ to $22 \mathrm{~mm}$ by daily transvaginal US examination or until serum estradiol levels, also denoted peak estradiol levels, reached $500 \mathrm{pg} / \mathrm{ml}$ (sample II). At that time, LA injections were discontinued and $10000 \mathrm{IU}$ hCG (Pregnyl, Organon) were administered. Ovum pick up (OPU) was scheduled 36$38 \mathrm{~h}$ after hCG injection and was performed under light sedation (sample III). Follicular fluid (sample IV) was aspirated (blood contaminated ff samples were not included in the total ff pool of each woman), centrifuged at 1500 r.p.m. and frozen at $-20^{\circ} \mathrm{C}$ for future analysis. There was no obvious contamination of $\mathrm{ff}$ by blood during the ovum pick up process. Daily progesterone (Utrogestan, Faran) luteal phase support was given until embryo transfer (ET), and 15 days later (sample V) pregnancy was assessed by serum $\beta$-hCG determination.

Embryo quality was assessed during the 2nd or 3rd day following IVF and was defined by the number of blastomeres $(<5$ and $>5)$ and the grade of fragmentation (on a scale of 1-4 with 4-3 = highest quality = grade $\mathrm{A}$ and $1-$ 2 = poorest quality = grade B). For statistical purposes, embryo quality was considered 'good' when the majority of transferred embryos had more than 5 blastomeres of grade $\mathrm{A}+\mathrm{B}$ and 'poor' when they had less than 5 blastomeres of grade $\mathrm{A}+\mathrm{B}$. The SPSS.10 package (SPSS, Chicago, IL, USA) was used for statistical analyses. Data were expressed as means \pm S.E.M. Mann-Whitney, Student's $t$ - and chisquare tests were used when appropriate and $P<0.05$ was considered statistically significant. For correlations between variables we used Pearson's correlation test.

Estradiol determinations were performed by radioimmunoassay and leptin by immunoradiometric assay (Diagnostic Systems Laboratories, Inc., Webster, TX, USA).

\section{Results \\ Clinical correlations between leptin, estradiol and BMI}

The transition from sample I to II induced by exogenous rFSH administration (29.45 $\pm 3.52 \mathrm{IU} /$ treatment), raised serum estradiol (409.72 $\pm 42.92 \mathrm{pg} / \mathrm{ml}$ (I) and $1689.08 \pm 134.52$ $\mathrm{pg} / \mathrm{ml}$ (II)) and leptin (44.09 $\pm 3.54 \mathrm{ng} / \mathrm{ml}$ (I) and $49.23 \pm 3.95 \mathrm{ng} / \mathrm{ml}(\mathrm{II}))$ levels more than 4 -fold $(P<0.001)$ and 1.2-fold $(P<0.05)$ respectively. The elevation of serum leptin levels from sample I to sample III $(52.10 \pm 4.27 \mathrm{ng} / \mathrm{ml}) \quad$ (oocyte retrieval) was 1.3 -fold $(P=0.001)$. The percentage change in leptin concentration from samples I to III was negatively associated with the number of retrieved oocytes $(r=-0.23, P=0.048)$ but not with the number of transferred embryos. The highest serum leptin levels were observed on OPU day. Follicular fluid leptin levels were significantly higher than leptin levels from all serum samples examined. No correlation was found between leptin and estradiol concentrations and their percentage response to $\mathrm{rFSH}$ administration in any of the serum samples examined.

As expected, BMI correlated positively with leptin in all the samples of our study group (Fig. 1) with the highest correlation seen in $\mathrm{ff}$ (sample IV). The BMI of IVF success women $\left(21.16 \pm 0.88 \mathrm{~kg} / \mathrm{m}^{2}\right)$ showed a higher correlation with ff leptin compared with that of IVF failure women (Fig. 2). The percentage change in leptin concentration (from sample I to sample III) did not correlate with the number of ampoules or the days of $\mathrm{rFSH}$ stimulation $(6.2 \pm 0.24$ days $)$.

\section{Clinical correlations and comparisons between leptin levels, embryo quality and IVF outcome}

Serum leptin concentrations of sample III had a positive correlation with ff leptin levels (sample IV) $(r=0.81$, 


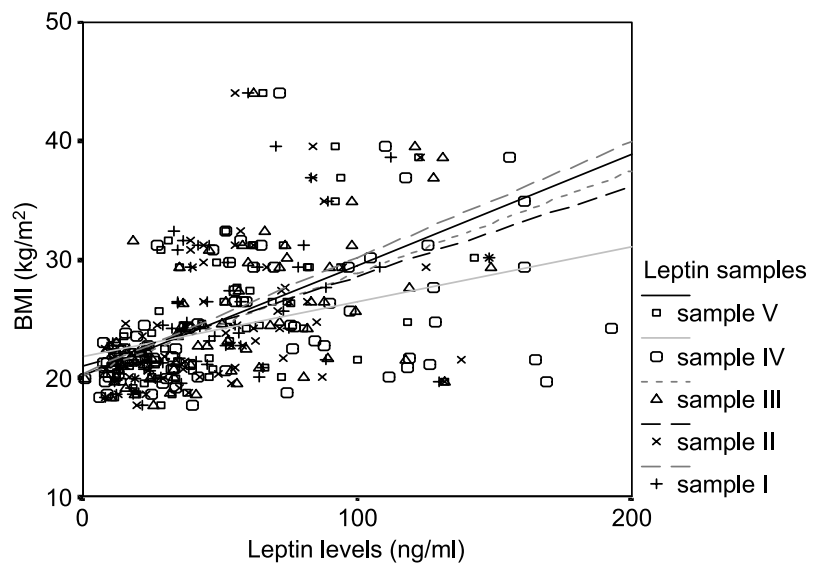

Figure 1 Correlation between $\mathrm{BMI}\left(\mathrm{kg} / \mathrm{m}^{2}\right)$ and serum and follicular fluid leptin levels. Sample I, $r=0.616, P<0.01$; sample II, $r=0.527, P<0.01$; sample III, $r=0.587, P<0.01$; sample IV, $r=0.670, P<0.001$; sample $\mathrm{V}, r=0.558, P<0.01$.

$P<0.001)$ and grade $\mathrm{A}$ and $<5$ blastomeres $(r=0.23$, $P=0.049$ ) embryo quality. Serum (sample III) and ff (sample IV) leptin levels of women with a positive $\beta$-hCG test $\quad(n=22) \quad(41.49 \pm 5.8 \mathrm{ng} / \mathrm{ml} \quad$ (sample III) and $49.1 \pm 7.21 \mathrm{ng} / \mathrm{ml}($ sample IV)) were lower from those of women with a negative $\beta$-hCG test $(n=78)$ $(56.87 \pm 5.52 \mathrm{ng} / \mathrm{ml}$ (sample III) and $68.65 \pm 7.53 \mathrm{ng} / \mathrm{ml}$ (sample IV)) $(P=0.026$ (sample III) and $P=0.014$ (sample IV)) (Fig. 3), a finding common to all samples from ART success (positive $\beta$-hCG test, pregnant) and failure women (negative $\beta$-hCG test, non-pregnant) (Table 1). The observed variation in leptin but not BMI of women categorized either according to estradiol levels on hCG administration day (Anifandis et al. 2005) or ART success/failure women (BMI of ART success women, $21.16 \pm 0.88 \mathrm{~kg} / \mathrm{m}^{2}$ and BMI of ART failure women, $23.14 \pm 0.85 \mathrm{~kg} / \mathrm{m}^{2}$, $P=$ not significant) suggests that the relative sensitivities of

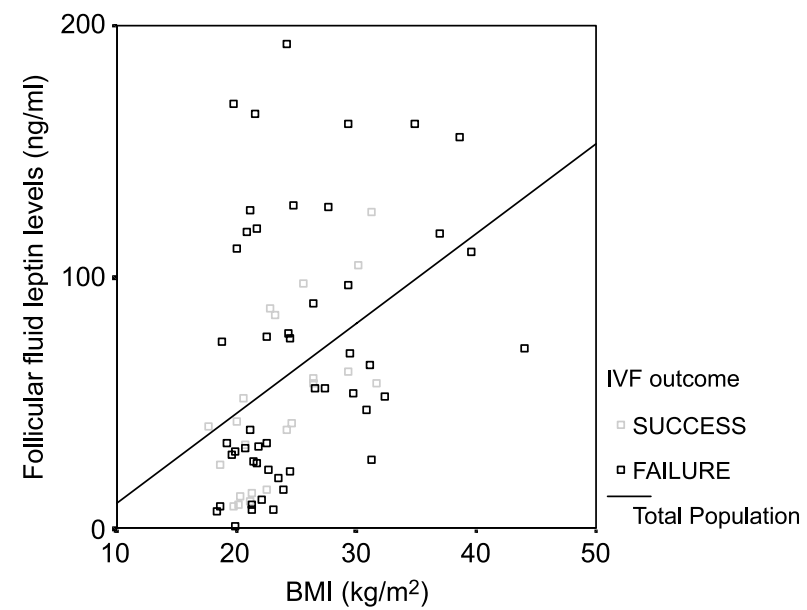

Figure 2 Correlation between follicular fluid leptin concentration and $\mathrm{BMI}\left(\mathrm{kg} / \mathrm{m}^{2}\right)$ in assisted reproductive technology (ART) success $(r=0.7, P<0.001)$ and ART failure $(r=0.35, P=0.01)$ women. these two parameters differ with leptin being a far more sensitive IVF marker compared with BMI. In agreement with the leptin levels and in contrast to BMI, embryo quality differed significantly between the two groups being of far superior quality in ART success women $(58 \%$ vs $32 \%$, $P<0.01$ ) (Table 1). We observed significantly lower leptin levels in women with 'good' $(50.05 \pm 5.6 \mathrm{ng} / \mathrm{ml}$ (sample III) and $60.92 \pm 7.04 \mathrm{ng} / \mathrm{ml}$ (sample IV)) compared with women with 'poor' $(59.48 \pm 7.6 \mathrm{ng} / \mathrm{ml}$ (sample III) and $69.5 \pm 10.95 \mathrm{ng} / \mathrm{ml} \quad$ (sample IV)) quality embryos $(P=0.047$ (sample III) and $P=0.039$ (sample IV)) (Fig. 3). The leptin levels of samples III and IV had borderline correlation with pregnancy rate $(P=0.056$ and $P=0.048$ respectively), in agreement with their proposed role as subfertility markers. This indicates that the leptin levels of sample III are better predictors of IVF outcome than any of the other serum samples.
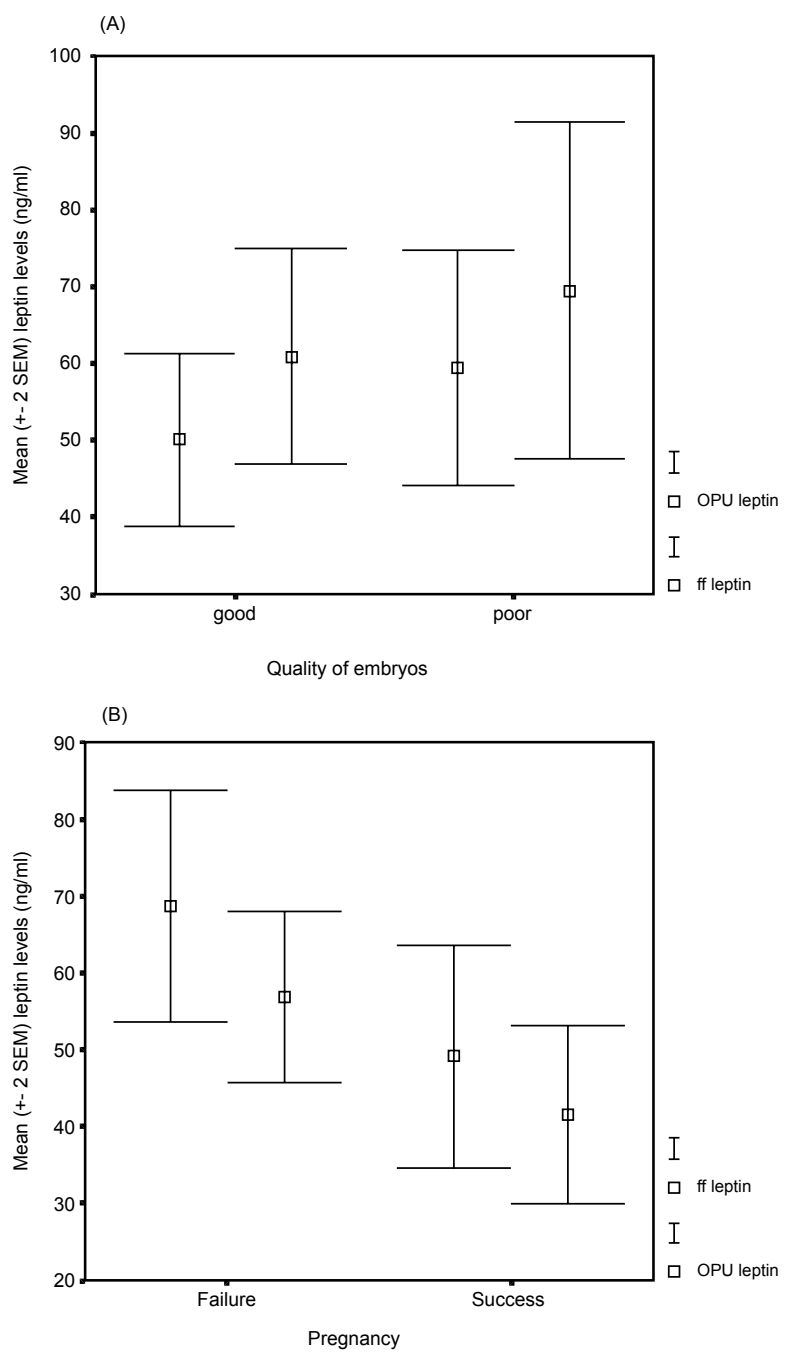

Figure 3 Effect of leptin on (A) embryo quality and (B) IVF outcome (pregnancy). 
Table 1 Biological characteristics of assisted reproductive technology (ART) success and failure women undergoing IVF (mean \pm S.E.M.). The numbers in parentheses denote the highest and the lowest value of any parameter determined.

\begin{tabular}{|c|c|c|}
\hline & ART success & ART failure \\
\hline No. of women & 22 & 78 \\
\hline Age (years) & $34.64 \pm 0.89$ & $35.47 \pm 0.73$ \\
\hline $\mathrm{BMl}\left(\mathrm{kg} / \mathrm{m}^{2}\right)$ & $21.16 \pm 0.88$ & $23.14 \pm 0.85$ \\
\hline $\mathrm{E}_{2}(\mathrm{pg} / \mathrm{ml})$ sample I & $390.45 \pm 68.89(50-1310)$ & $418.37 \pm 54.36(65-1650)$ \\
\hline $\mathrm{E}_{2}(\mathrm{pg} / \mathrm{ml})$ sample II & $1697.73 \pm 199.7(500-4060)$ & $1685.2 \pm 174.3(500-5410)$ \\
\hline $\mathrm{E}_{2}(\mathrm{pg} / \mathrm{ml})$ sample III & $1318.2 \pm 183.2(300-3810)$ & $1188.9 \pm 807.6(165-4010)$ \\
\hline $\mathrm{E}_{2}(\mathrm{pg} / \mathrm{ml})$ sample $\mathrm{V}$ & $813.27 \pm 142.93(30-2620)^{*}$ & $50.92 \pm 16.18(10-80)$ \\
\hline Leptin (ng/ml) sample I & $37.65 \pm 6.76(11.1-148.2) * *$ & $46.98 \pm 4.12(8.25-130)$ \\
\hline Leptin $(\mathrm{ng} / \mathrm{ml})$ sample II & $43.18 \pm 6.6(8.30-147.9) *$ & $51.94 \pm 4.88(8.15-138)$ \\
\hline Leptin (ng/ml) sample III & $41.49 \pm 5.8(8.20-99.1) * *$ & $56.87 \pm 5.52(0.77-148.7)$ \\
\hline Ff leptin (ng/ml) sample IV & $49.1 \pm 7.21(8.38-125.84) * *$ & $68.65 \pm 7.53(0.88-192.8)$ \\
\hline Leptin (ng/ml) sample V & $43.66 \pm 6.32(7.2-142.3) * *$ & $50.08 \pm 4.63(7.5-131.7)$ \\
\hline No. of $\mathrm{rFSH}$ ampoules ${ }^{1}$ & $32.09 \pm 3.18(13-72) * *$ & $28.26 \pm 1.79(7-60)$ \\
\hline Stimulation days & $6.04 \pm 0.38(4-11)$ & $6.61 \pm 0.24(4-10)$ \\
\hline No. of retrieved oocytes & $6.68 \pm 0.95(2-21)$ & $6.32 \pm 0.49(2-16)$ \\
\hline No. of phase II (mature) oocytes & $6.27 \pm 0.98(2-21) * *$ & $5.34 \pm 0.45(1-14)$ \\
\hline Fertilization rate $(\%)$ & $69.91 \pm 4.4^{* *}$ & $52.99 \pm 3.34$ \\
\hline No. of transferred embryos & $3.81 \pm 0.33(1-6)$ & $3.18 \pm 0.24(1-6)$ \\
\hline Embryos with $\geq 5$ blastomeres and grade $\mathrm{A}$ & $1.91 \pm 0.41(0-6) *$ & $0.78 \pm 0.25(0-6)$ \\
\hline Embryos with $\geq 5$ blastomeres and grade $B$ & $0.3 \pm 0.11(0-2)$ & $0.24 \pm 0.094(0-4)$ \\
\hline Embryos with $<5$ blastomeres and grade $\mathrm{A}$ & $0.53 \pm 0.27(0-4)$ & $0.85 \pm 0.21(0-3)$ \\
\hline Embryos with $<5$ blastomeres and grade $\mathrm{B}$ & $0.14 \pm 0.02(0-5) *$ & $0.59 \pm 0.14(0-4)$ \\
\hline 'Good' quality embryos ${ }^{2}$ & $58 \% * *$ & $32 \%$ \\
\hline 'Poor' quality embryos ${ }^{2}$ & $22 \% * *$ & $44 \%$ \\
\hline
\end{tabular}

${ }^{1}$ Ampoules of $75 \mathrm{IU}$ were used.

${ }^{2}$ The remaining $10 \%(100 \%-(58+32) \%)$ and $34 \%(100 \%-(22+44) \%)$ of ART success and ART failure women respectively produced embryos of equal quality, meaning that they had an equal number of 'good' and 'poor' quality transferred embryos.

${ }^{*} P<0.05,{ }^{*} P<0.01$ significant difference between the two compared groups.

\section{Discussion}

We report serum and ff leptin levels during critical stages of the ART procedure in an attempt to confirm a direct role of leptin at the level of embryo quality. For this purpose, the levels of leptin were correlated with the number of competent oocytes, embryo quality, estradiol and BMI of pregnant and non-pregnant women, in the five samples detailed in the Subjects and methods section. We found no correlation between serum leptin and estradiol, a wellknown potent ovarian stimulator, in any of the samples examined, nor in their percentage change from samples I to II, suggesting that leptin is not a reliable indicator of ovarian stimulation in our study group, in contrast to estradiol. This lack of correlation suggested that estradiol and leptin might have opposing roles during ovarian stimulation. Their parallel, although disproportional, elevation on the day of hCG administration, however, has been shown to have a negative influence on IVF-ET outcome, in agreement with our recent report (Anifandis et al. 2005).

The percentage increase in leptin levels between samples I and III was associated with a reduced number of competent oocytes. This finding suggested that high intra-ovarian leptin levels present on the OPU day (sample III) suppressed the ovarian response to gonadotropins, ovarian steroidogenesis and estradiol production, follicle maturation, and oocyte competence and yield, reducing overall pregnancy rate. Likewise, the lower leptin concentrations of ART success women and their stronger correlation to BMI (Fig. 2) were consistent with this finding. A previous report suggested that low leptin concentrations improved the pregnancy rate (Mantzoros et al. 2000), in agreement with our findings (Fig. 3). In contrast, however, pregnancy was correlated with higher leptin values 12 days after embryo transfer (Unkila-Kallio et al. 2001). The reason for this discrepancy is presently unknown.

Leptin concentrations varied significantly between the different samples examined. They were highest in ff (sample IV) and, among the serum samples, on OPU (sample III) (Table 1). Only the OPU and ff leptin concentrations correlated positively with pregnancy rate. Given their strong correlation to BMI (Fig. 1), our findings suggest that $\mathrm{ff}$ leptin levels may serve as a subfertility marker. In our previous (Anifandis et al. 2005) and present studies, the subjects were grouped according to their serum estradiol level and IVF outcome respectively. Either method of patient classification revealed significant differences only in leptin and not in BMI suggesting that the former is a more sensitive prognostic marker of specific reproductive aspects such as embryo quality. The negative influence of leptin on embryo quality originally suggested in our previous report (Anifandis et al. 2005) and confirmed in this study, supports its direct effect on embryo quality that may also influence IVF outcome. 
In our study, OPU (sample III) and ff (sample IV) leptin levels in excess of $59.48 \pm 7.6 \mathrm{ng} / \mathrm{ml}$ and $69.5 \pm 10.95 \mathrm{ng} / \mathrm{ml}$ respectively, affected negatively the quality of transferred embryos. This elevation may suppress oocyte maturation causing poor embryo development and implantation ability. The positive association of ff leptin levels with 'poor' embryo quality (grade A, $<5$ blastomeres) and the significant difference in leptin concentrations between women producing 'good' versus 'poor' quality embryos, is in line with this possibility. Our findings agree with a previous report suggesting predictive association between embryo quality and ff leptin, VEGF and NO concentrations (Barroso et al. 1999) and disagree with another study reporting that serum and $\mathrm{ff}$ leptin and soluble leptin receptor concentrations are unsuitable markers of oocyte maturation or embryo quality (Welt et al. 2003).

Functional leptin receptors and the STAT3 signal transduction pathway mediate the direct role of leptin on oocyte maturation, fertilized oocyte pre-implantantion and early stage porcine embryo development (Antczak \& Van Blerkom 1997). A similar mechanism may explain the observed conditional direct role of leptin on human embryo quality, with ART success women presenting lower leptin levels and more good quality embryos compared with ART failure women (Fig. 3).

In summary, we observed significantly lower leptin levels (in both serum and ff, samples III and IV) in women with 'good' compared with women with 'poor' quality embryos (Fig. 3). We also observed a negative correlation between percentage leptin increase in response to $\mathrm{rFSH}$ administration (samples I to III) and reduced ovarian responsiveness, oocyte maturation and competence. These findings suggest that serum leptin concentrations in sample III, in excess of $59.48 \pm 7.6 \mathrm{ng} / \mathrm{ml}$ and $56.87 \pm 5.52 \mathrm{ng} / \mathrm{ml}$, may be useful prognostic indicators of 'poor' embryo quality and IVF failure respectively. They also support a more sensitive role of leptin relative to $\mathrm{BMI}$ in direct functional staging of ART at the level of embryo quality. In the previous and present studies we used different criteria for patient classification. Interestingly, the range of leptin levels associated with optimal embryo quality and IVF outcome was similar if not identical between the two subject groups. This finding strengthens the prognostic value of serum leptin within the concentration range specified in our studies, as a sensitive regulator of human embryo quality that may influence IVF outcome. The combined prognostic IVF value of all three parameters (BMI, estradiol and leptin) recorded in the two subject groups studied is currently being evaluated.

\section{References}

Anifandis G, Koutselini E, Louridas K, Liakopoulos V, Leivaditis K, Mantzavinos T, Sioutopoulou D \& Vamvakopoulos N 2005 Leptin and estradiol as conditional prognostic IVF markers. Reproduction $129531-534$.
Antczak M \& Van Blerkom J 1997 Oocyte influences on embryo development: the regulatory proteins leptin and STAT3 are polarized in mouse and human oocytes and differentially distributed within the cells of the pre-implantation stage embryo. Molecular Human Reproduction 3 1067-1086.

Barash IA, Cheung CC, Weigle DS, Ren H, Kabigting EB, Kuijper JL, Clifton DK \& Steiner RA 1996 Leptin is a metabolic signal to the reproductive system. Endocrinology 137 3144-3147.

Barroso G, Barrionuevo M, Rao P, Graham L, Danforth D, Huey S, Abuhamed A \& Oehninger S 1999 Vascular endothelial growth factor, nitric oxide, and leptin follicular fluid leptin levels correlate negatively with embryo quality in IVF patients. Fertility and Sterility 72 1024-1072.

Brannian J, Schmidt D, Kreger D \& Hansen K 2001 Baseline non-fasting serum leptin concentrations to body mass index ratio is predictive of IVF outcomes. Human Reproduction 16 1819-1826.

Butzow TL, Moilanen JM, Lehtovirta M, Tuomi T, Hovatta $O$, Siegberg R, Nilsson CG \& Apter D 1999 Serum and follicular leptin during in vitro fertilization: relationship among leptin increase, body fat mass and reduced ovarian response. Journal of Clinical Endocrinology and Metabolism 84 3135-3139.

Cheung CC, Thornton JE, Kuijper JL, Weigle DS, Clifton DK \& Steiner RA 1997 Leptin is a metabolic gate for the onset of puberty in the female rat. Endocrinology 138 855-858.

Cioffi J, Van Blerkom J, Antczak M, Shafer A, Wittmor S \& Snodgrass HR 1997 The expression of leptin and its receptors in preovulatory human follicles. Molecular Human Reproduction 3 467-472.

El-Hefnawy T, Loffe S \& Dym M 2000 Expression of the leptin receptor during germ cell development in the mouse testis. Endocrinology $1412624-2630$.

Hardie L, Trayhurn P, Abramovich D \& Fowler P 1997 Circulating leptin in women: a longitudinal study in the menstrual cycle and during pregnancy. Clinical Endocrinology 47 101-106.

Mannuci E, Ognibene A, Becorpi A, Cremasco F, Pellegrini S, Ottanelli S, Rizzello SM, Massi G, Messeri G \& Rolella CM 1998 Relationship between leptin and oestrogens in healthy women. European Journal of Endocrinology 139 198-201.

Mantzoros CS, Cramer DW, Liberman RF \& Barbieri RC 2000 Predictive value of serum and follicular fluid leptin concentrations during assisted reproductive cycles in normal women and in women with polycystic ovarian syndrome. Human Reproduction 15 539-544.

Nomikos IN \& Vamvakopoulos NC 2001 Correlating functional staging to effective treatment of acute surgical illness. American Journal of Surgery 182 278-286.

Riad-Gabriel MG, Jinagouda SD, Sharma A, Boyadjian R \& Saad MF 1998 Changes in plasma leptin during the menstrual cycle. European Journal of Endocrinology 139 528-531.

Unkila-Kallio L, Andersson S, Koistinen HA, Karonen SL, Ylikorkala O \& Tiitinen A 2001 Leptin during assisted reproductive cycles: the effect of ovarian stimulation and of very early pregnancy. Human Reproduction 16 657-662.

Welt CK, Schneyer AL, Heist K \& Mantzoros CS 2003 Leptin and soluble leptin receptor in follicular fluid. Journal of Assisted Reproduction and Genetics 20 495-501.

Zhang Y, Proenca R, Maffei M, Barone M, Leopold A \& Friedman JM 1994 Positional cloning of the obese gene and its human homologue. Nature 372 425-432.

Received 24 February 2005

First decision 7 July 2005

Revised manuscript received 22 July 2005

Accepted 22 August 2005 